\title{
Empirical Assessment of Bacillus Calmette-Guérin Vaccine to Combat COVID-19
}

\section{Nikita Jain ${ }^{1}$, Vedika Gupta ${ }^{1, *}$, Chinmay Chakraborty ${ }^{2}$, Agam Madan $^{1}$, Deepali Virmani ${ }^{3}$, Lorenzo Salas-Morera ${ }^{4}$ and Laura Garcia-Hernandez ${ }^{4}$}

\footnotetext{
${ }^{1}$ Department of Computer Science \& Engineering, Bharati Vidyapeeth's College of Engineering, New Delhi, 110063, India

${ }^{2}$ Department of Electronics \& Communication Engineering, Birla Institute of Technology, Mesra, 814142, India

${ }^{3}$ Department of Computer Science \& Engineering, Bhagwan Parshuram Institute of Technology, New Delhi, 110063, India

${ }^{4}$ Area of Project Engineering, University of Córdoba, Córdoba, 14071, Spain

*Corresponding Author: Vedika Gupta. Email: vedika.gupta@bharatividyapeeth.edu

Received: 02 January 2021; Accepted: 24 April 2021
}

\begin{abstract}
COVID-19 has become one of the critical health issues globally, which surfaced first in latter part of the year 2019. It is the topmost concern for many nations' governments as the contagious virus started mushrooming over adjacent regions of infected areas. In 1980, a vaccine called Bacillus Calmette-Guérin (BCG) was introduced for preventing tuberculosis and lung cancer. Countries that have made the BCG vaccine mandatory have witnessed a lesser COVID-19 fatality rate than the countries that have not made it compulsory. This paper's initial research shows that the countries with a longterm compulsory BCG vaccination system are less affected by COVID-19 than those without a BCG vaccination system. This paper discusses analytical data patterns for medical applications regarding COVID-19 impact on countries with mandatory BCG status on fatality rates. The paper has tackled numerous analytical challenges to realize the full potential of heterogeneous data. An analogy is drawn to demonstrate how other factors can affect fatality and infection rates other than BCG vaccination only, such as age groups affected, other diseases, and stringency index. The data of Spain, Portugal, and Germany have been taken for a case study of BCG impact analysis.
\end{abstract}

Keywords: Bacillus Calmette-Guérin; COVID-19; fatality rate; lockdown; gross domestic product; vaccine

\section{Introduction}

In December 2019, initial cases of people suffering from acute respiratory syndrome coronavirus 2 (SARS-CoV 2) were reported in Wuhan, China. The entire world has been dealing with unforeseen challenges caused by the COVID-19 pandemic since December 2019. According to the latest report of the World Health Organization (WHO), this virus has infected 20 million populations, and it already caused 744,385 deaths across the world. ${ }^{1}$ With a severe mortality

\footnotetext{
1 https://ourworldindata.org/coronavirus-testing.
}

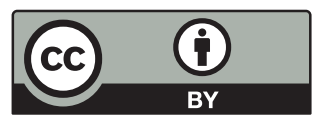

This work is licensed under a Creative Commons Attribution 4.0 International License, which permits unrestricted use, distribution, and reproduction in any medium, provided the original work is properly cited. 
rate as compared to the last two significant epidemics, namely SARS (2002) and Middle East Respiratory Syndrome (MERS) (2012), COVID-19 is a declared pandemic for the mankind. Intelligent data processing systems can improve medical diagnosis and subsequent treatment with follow-up of diagnostic operations. The clinical analytical processes can be mechanized for various medical conditions that can enhance clinical therapy inspection based on BCG vaccination.

Currently, no approved treatment or reliable vaccine is available for controlling COVID-19. Researchers and scientists are continually striving to find effective therapeutic agents and a SARSCoV-2 infection vaccine. Many existing vaccination policies are being revisited instead of finding possible means to combat this virus's effects or occurrence in human bodies. A recent coverage [1] on the vaccine Bacillus Calmette-Guérin vaccine discovered in 1921 that has served as a protection against tuberculosis, and its complications show the potential against fighting Tuberculosis (TB) and Cancer [2]. In particular, several epidemiological [3,4] and immunological studies [5,6] indicate that BCG vaccination contributes to reducing morbidity and mortality in similar infections, in children and as well in adults [7]. These findings derive their explanation from the vaccine's likelihood benefit on the immune system [8]. Hence, various recent research studies reported associating BCG vaccination with COVID-19, supporting [9,10] and contradicting [11,12] such findings. Similar studies were conducted to analyze certain monotherapeutic agents' impact, such as hydroxychloroquine, on COVID-19 fatality rates [13].

Further, Reference [14] hypothesized a significant reduction in COVID-19 infections and subsequent death rates in the population sectors that followed mandatory BCG policies [15]. The idea of BCG being an aid to lower the COVID-19 fatality rate has been studied and empirically assessed in this paper. Before making strategies to fight this virus, it is essential to know people's state of mind, emotions, and concerns [16-18]. This paper aims to explain this issue by providing epidemiological illustrations of the association between BCG immunization and COVID-19 mortality worldwide.

Based on the above assessment criterion, it can be contemplated that BCG vaccination may be a powerful preventive measure against SARS-CoV-2 infection. It may also reduce the incidence of COVID-19 disease [19,20]. The assessment presented in this paper processes divergent data that can form a basis to inspect that there may be a correlation between reduced infection level and less COVID-19 related fatality rates. This correlation has been observed based on the period that the BCG vaccine has been recommended in various countries, viz. Spain, Portugal, and Germany. The study conducted in this paper envisions that important insights can be unearthed about COVID-19 and BCG clinical trials [21]. For instance, some insights that can come from this study are whether variables like the BCG strain, the age at which people are vaccinated, revaccination, or how long people are vaccinated are relevant or not. This paper can support the role of BCG vaccinations or a related proposition based on empirical data analytics. This paper aims to understand the analytical and empirical impact of COVID-19 worldwide and ascertain if there is any influence on the disease's severity based on the country's BCG vaccine policy. For the study conducted in the paper, data has been collected from disparate sources, making it heterogeneous (missing values and noisy labels). The data under study capture various dimensions of COVID-19 statistics in terms of age, fatality rate, presence of other diseases, income status, and BCG status. 
This paper presents indicative studies to tackle numerous challenges in analyzing and inspecting heterogeneous data's divergent and yet sagacious prospects. The main contributions of this paper are as follows:

1) A thorough analysis of COVID-19 cases by using a case study of different high and less infected countries. This paper presents the first study of BCG correlation with COVID-19 mortality to the best of our knowledge.

2) A case study analysis of how BCG mandatory vaccination status has led to a flattened fatality curve for several counties, namely Spain, Portugal, and two German provinces.

3) Diagnosing the presence of other essential factors such as stringency index, age group, and other diseases can lead to flattened fatality rate curves such as stringency index, age group, and other diseases.

We discuss answers to the following groundbreaking questions:

- Is the fatality rate consistent in the countries where BCG is mandatory? If it is different, what is the reason for the difference?

- How do the COVID-19 cases vary in two neighboring countries, namely Spain and Portugal, based on different BCG vaccine coverage?

- Does the BCG vaccine provide COVID-19 protection in individuals belonging to the high age groups?

- How does the impact of COVID-19 vary in the east and west part of Germany?

The rest of the paper has been arranged in the following manner. Section 2 reflects the findings and analysis conducted regarding the impact of COVID-19 concerning BCG status and other factors that can play a key role in determining the COVID fatality rate. Section 3 represents the COVID-19 cases in different countries, where a direct comparison between the BCG status and COVID deaths is drawn. Section 4 inspects the analytical findings and empirical assessment regarding BCG vaccination's impact on COVID-19 infections and fatality statistics. Section 5 concludes the entire paper by representing inferences derived from the conducted analytical and empirical analysis.

\section{Visualizations}

The data ${ }^{1,2}$ available for COVID-19, shows that the disease's incidence and mortality often differ significantly among countries. The variability may be attributed to several factors like race [22], dietary patterns, environment [23], social behaviors [24], genetic differences, and systems of governance. Comprehensive empirical evaluations and trend studies have been conducted that explore the variation and correlation in the COVID-19 fatality rate and BCG vaccination policy status.

The time plot of Fig. 1 shows the increase in the number of COVID-19 cases throughout time for the top 10 countries with the most number of cases. Further, Fig. 2 shows the increase in COVID-19 deaths throughout time for the top 10 countries with the most deaths.

\footnotetext{
2 https://github.com/owid/covid-19-data/tree/master/public/data.
} 


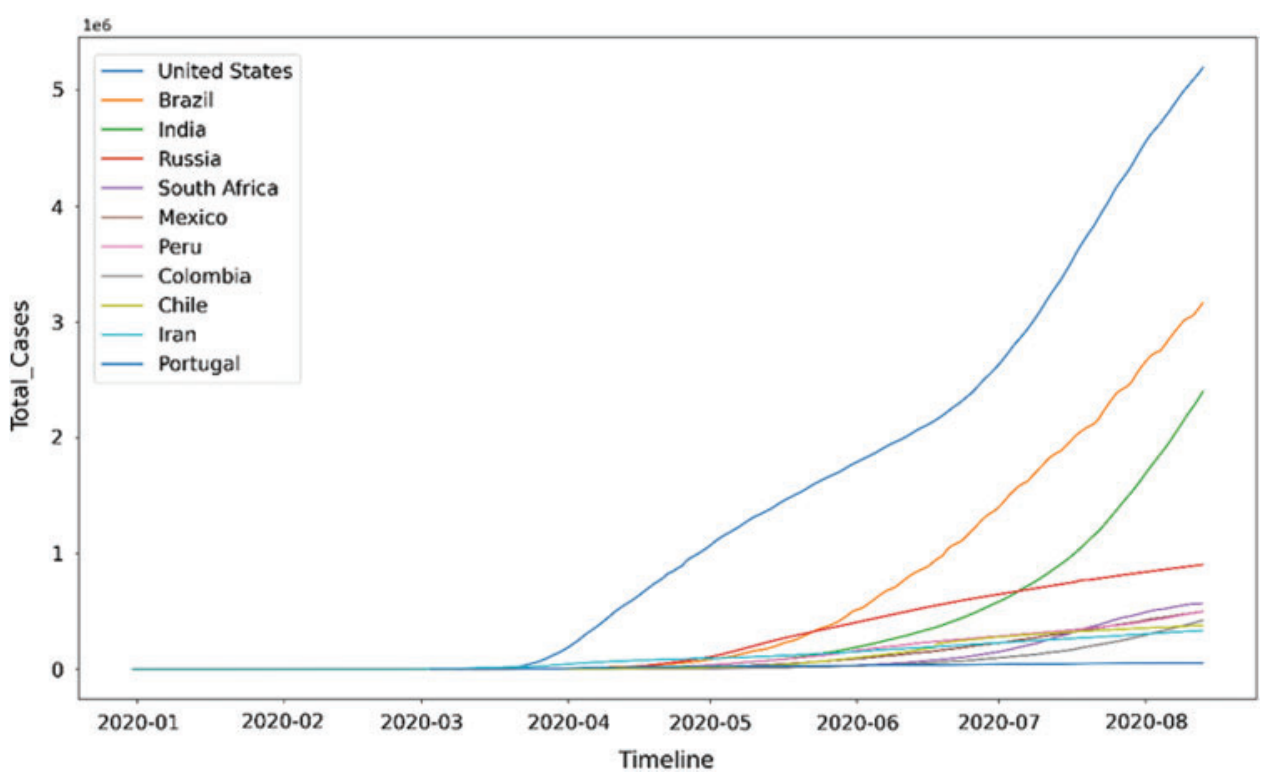

Figure 1: Time plot for COVID-19 cases $^{2}$

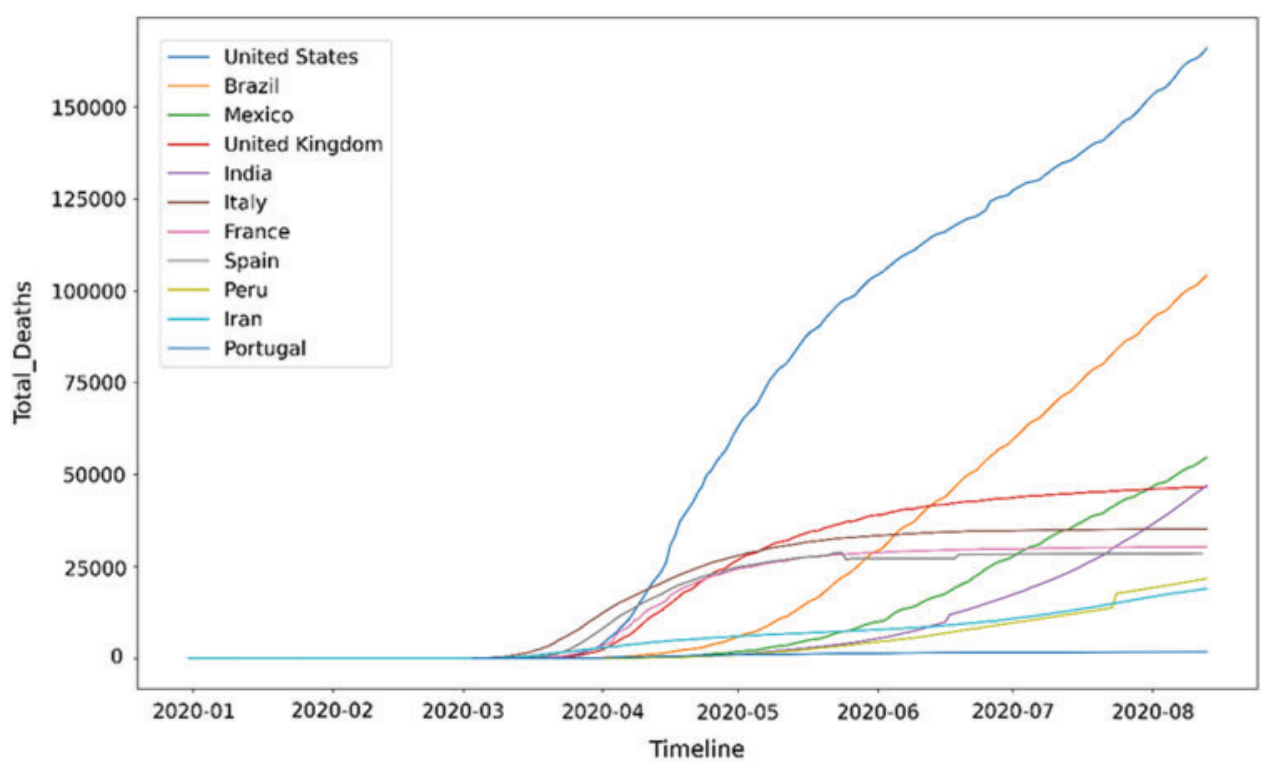

Figure 2: Time plot for COVID-19 deaths

Figs. 1 and 2 postulates the following inferences:

1) A significant number of countries seem to have a fatality rate between $0-5 \%$.

2) European countries, namely Belgium, United Kingdom (UK), France, Netherlands, and Italy, stand out of the pack when it comes to fatality rate. Belgium has a $15 \%$ fatality rate, which means that out of every 100 COVID-19 patients, 15 patients die. This number is much higher than the rest of the world. 
3) Mexico has the highest fatality rate in North America, i.e., more than 10\%, much higher than the United States' death rate.

4) Ecuador has the highest fatality rate in South America, and it is more than $10 \%$.

5) Middle East countries like Qatar, Bahrain, and Saudi Arabia have conducted the highest tests per million people.

It is also observed that the countries with high-income have a higher number of COVID-19 death cases than the countries with low-income. Many countries, such as Nigeria, India, Pakistan, and Peru, have fewer tests and lower death rates.

Fig. $3 \mathrm{a}$ presents the fatality rate variation concerning the total cases per million of COVID-19. This graphical depiction helps to understand the existence of correlation, if any. Fig. $3 b$ shows the number of testing done by having different bubble sizes for total tests conducted per thousand people for the available data. These plots have been given for countries with more than 100000 cases to clarify the image using the dataset. ${ }^{3}$

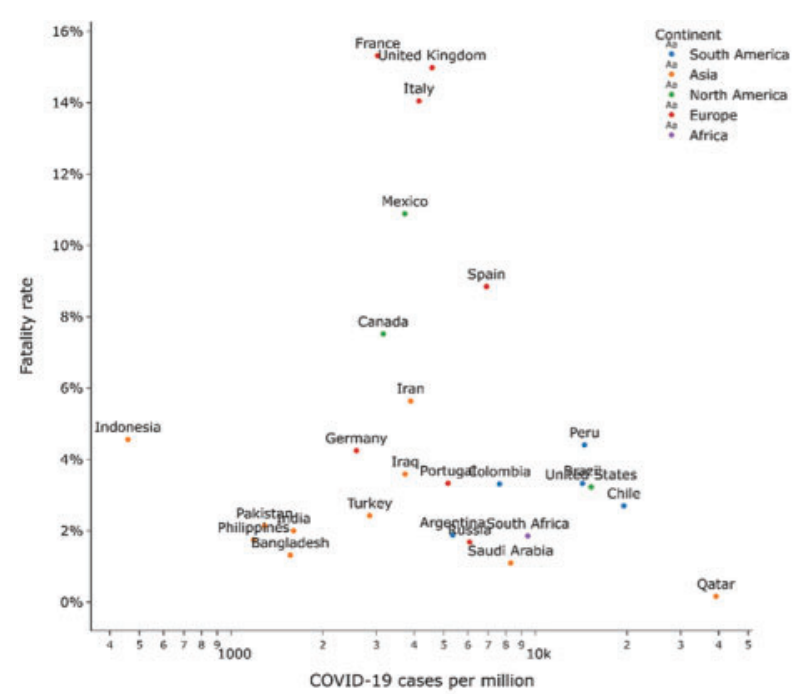

(a)

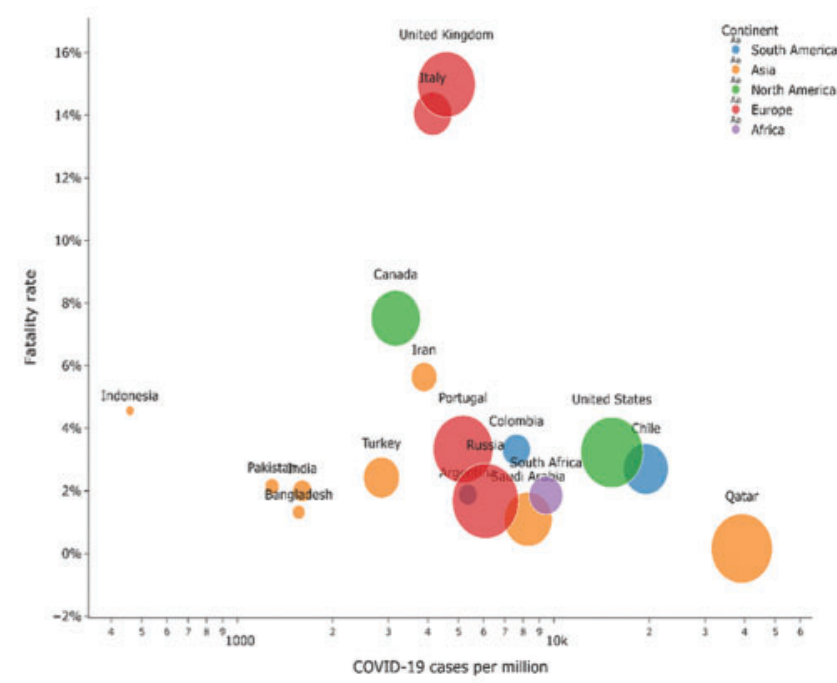

(b)

Figure 3: (a) Fatality Rate vs. COVID-19 cases (b) Number of tests conducted country-wise

Most countries report a fatality rate between $0 \%$ and $6 \%$. European countries show a high fatality rate compared to other nations in general, which may result from a large number of testing being done in these developed countries or related to the BCG policies opted by these countries. Countries having high Gross Domestic Product (GDP) per capita have more cases. It is because of conducting more number of COVID-19 tests. Fig. 4 shows the correlations between various factors viz. Total cases with deaths and population, Median age with GDP, and hospital beds per thousands are available in the datasets used to determine their relationship with another. Most of the factors seem to have a weak or no correlation with one another. Although some correlations seem to exist between some factors like:

- Total cases and total deaths: 0.95

- Total cases and population: 0.72

\footnotetext{
${ }^{3}$ https://github.com/owid/covid-19-data/tree/master/public/data.
} 
- Total deaths and population: 0.71

- GDP per capita and median age: 0.79

- Median age and hospital beds per thousand: 0.6

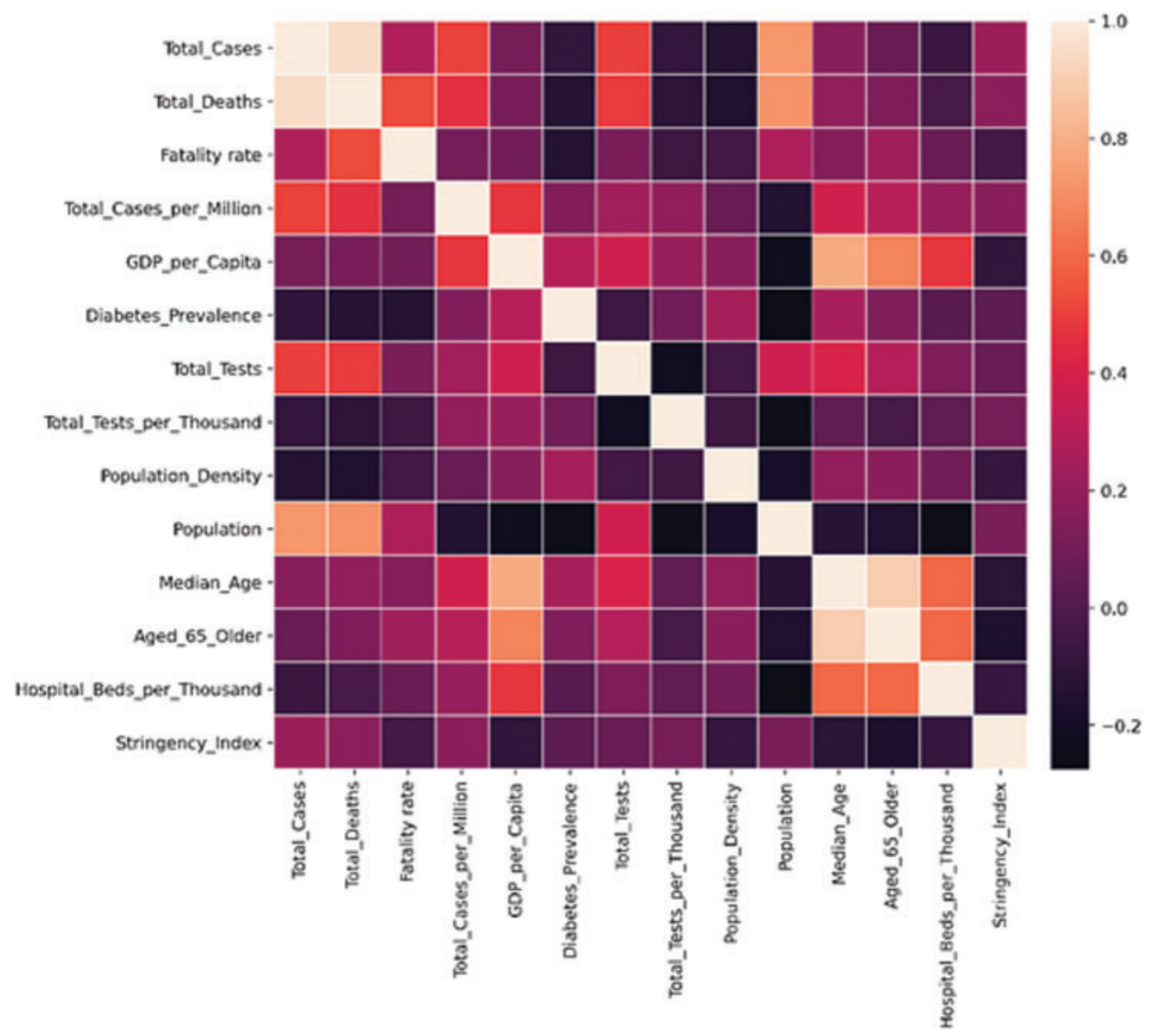

Figure 4: Correlation matrix for various factors that may impact COVID-19 cases and deaths

Figs. $5 \mathrm{a}$ and $5 \mathrm{~b}$ shows that the majority of countries with a high fatality rate are in Europe (France, United Kingdom, Italy, and Belgium), and the majority of countries with a low fatality rate are in Asia (Bahrain, Nepal, Qatar, and Singapore). Figs. 6a and 6b presents the time series for the variation of fatality rates in these countries Most countries with high fatality rates face their first deaths around the last week of February and the first week of March due to China's incoming travelers. All of these countries show fatality rates of over $10 \%$.

The countries with the low fatality rates are small countries with a small population, and the fatality rates mostly remain beneath $1 \%$. Tabs. 1 and 2 presents the BCG status for all these countries obtained from the conducted assessment.

Interestingly, most countries with the highest fatality rates do not have a current mandatory BCG vaccination policy for all. In contrast, the countries with lower fatality rates have a current BCG vaccination policy for all. Fig. 7 provides the plot for the current BCG vaccination status against the fatality rate The median fatality rate for countries with the current BCG vaccination policy is around $2 \%$. Fig. 7 presents the comparison, the median fatality rate for countries without BCG vaccination policy is nearly $4 \%$ and is. 


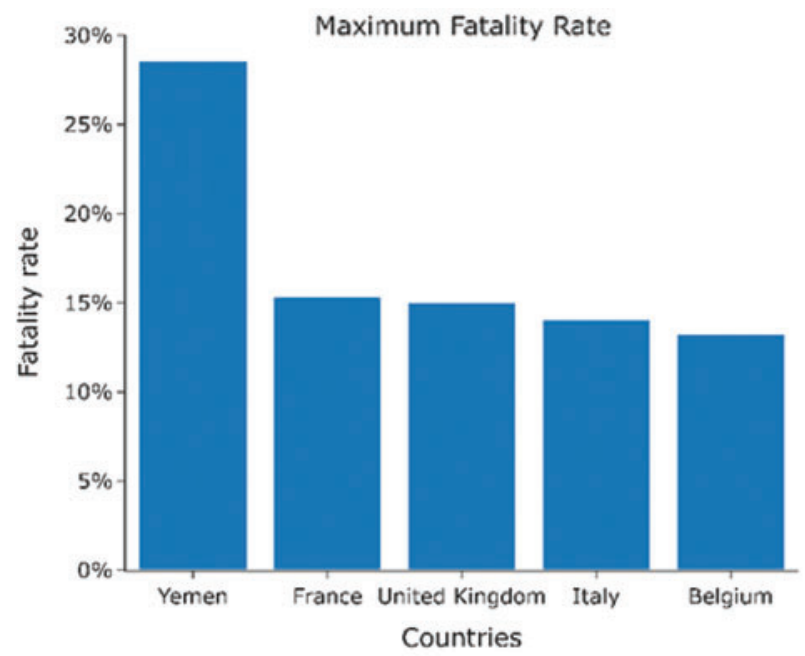

(a)

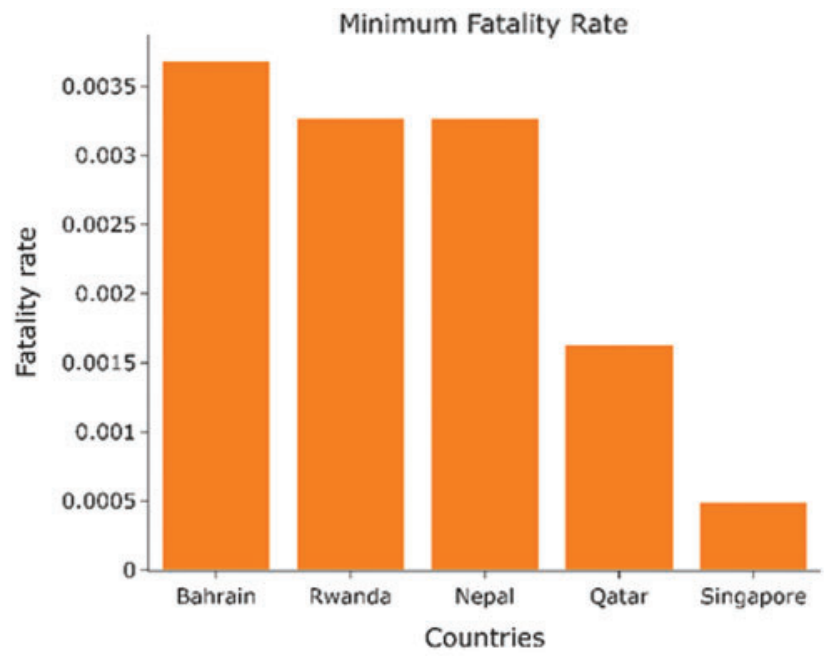

(b)

Figure 5: (a) Countries with the highest fatality rates. (b) Countries with the lowest fatality rates

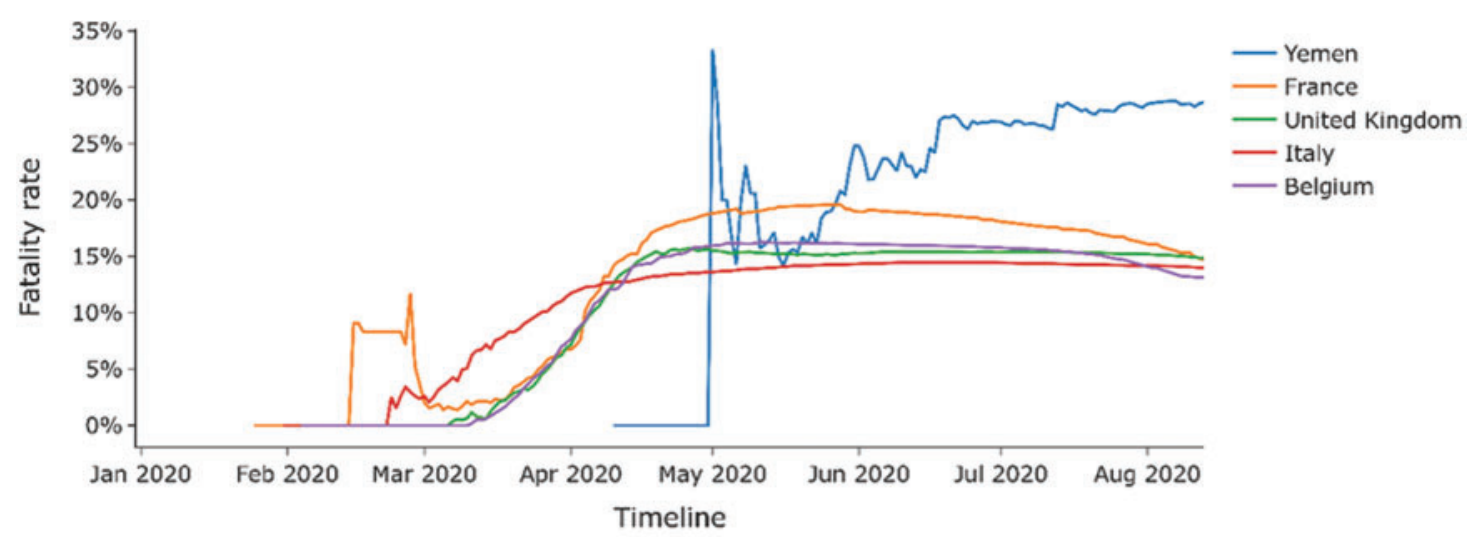

(a)

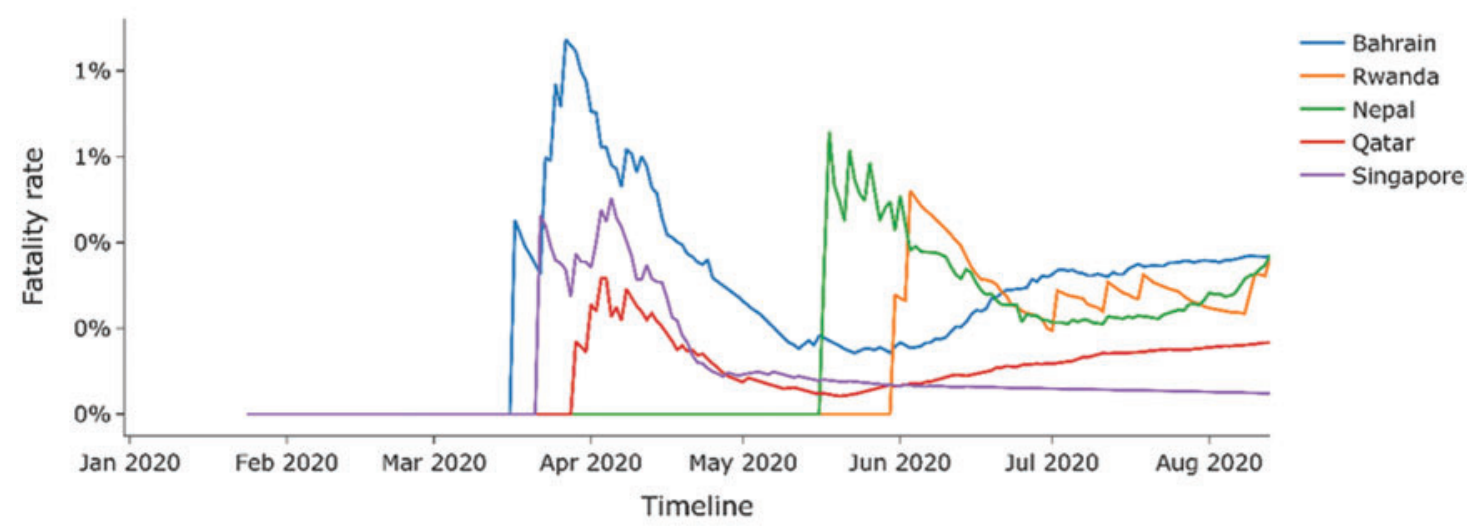

(b)

Figure 6: (a) Time series analysis for countries with highest fatality rates. (b) Time series analysis for countries with the lowest fatality rates 
Table 1: Status of BCG vaccination in countries with high fatality rates

\begin{tabular}{|c|c|c|}
\hline Country & Current BCG status & BCG recommendation \\
\hline Yemen & Yes & $\begin{array}{l}\text { Current national BCG vaccination policy for all } \\
\text { during birth. }\end{array}$ \\
\hline France & No & $\begin{array}{l}\text { Past national BCG vaccination policy for all } \\
\text { during birth. }\end{array}$ \\
\hline United Kingdom & No & $\begin{array}{l}\text { Past national } \mathrm{BCG} \text { vaccination policy for all } \\
\text { after infancy ( } 12 \text { or } 13 \text { years old) }\end{array}$ \\
\hline Italy & No & $\begin{array}{l}\text { BCG recommendation only for specific groups or } \\
\text { none at all. }\end{array}$ \\
\hline Belgium & No & $\begin{array}{l}\text { BCG recommendation only for specific groups or } \\
\text { none at all. }\end{array}$ \\
\hline
\end{tabular}

Table 2: Status of BCG vaccination in countries with low fatality rates

\begin{tabular}{lll}
\hline Country & Current BCG status & BCG recommendation \\
\hline Rwanda & Yes & $\begin{array}{l}\text { Current national BCG vaccination policy for all } \\
\text { during birth. }\end{array}$ \\
Nepal & Yes & $\begin{array}{l}\text { Current national BCG vaccination policy for all } \\
\text { after birth within one year. } \\
\text { Current national BCG vaccination policy for all } \\
\text { during birth. }\end{array}$ \\
Satar & Yes & $\begin{array}{l}\text { Current national BCG vaccination policy for all } \\
\text { during birth. }\end{array}$ \\
\hline
\end{tabular}

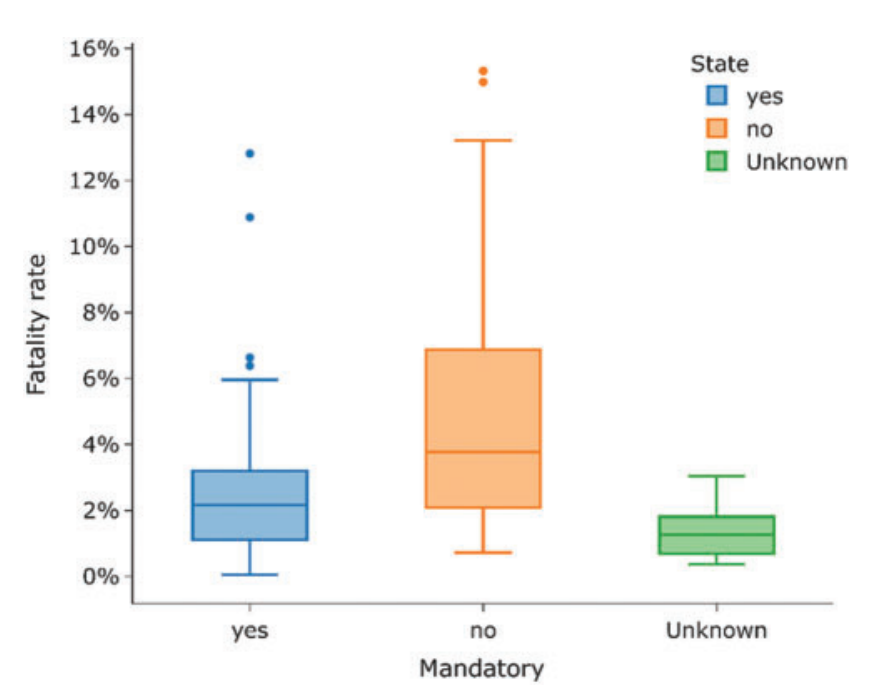

Figure 7: Current status for BCG vaccination and its correlation with the fatality rate 
For further insights, a BCG coverage analysis is presented in Fig. 8, which shows the percentage of BCG coverage for different regions defined by WHO from 1980 to 2019. The information source is captured by a global repository ${ }^{4}$ of data provided by the WHO-United Nations Children Fund (UNICEF). The South-East Asia Region has the highest percentage BCG coverage of 95.27\% till 2019. The European region has the lowest percentage BCG coverage of $61.09 \%$, as $\mathrm{BCG}$ vaccination is not mandatory in most countries in Europe due to fewer cases. Tab. 3 shows the distribution of BCG strains used by countries on different continents. Fig. 9 shows the fatality rate $v$. different strains of BCG vaccine used in other countries.

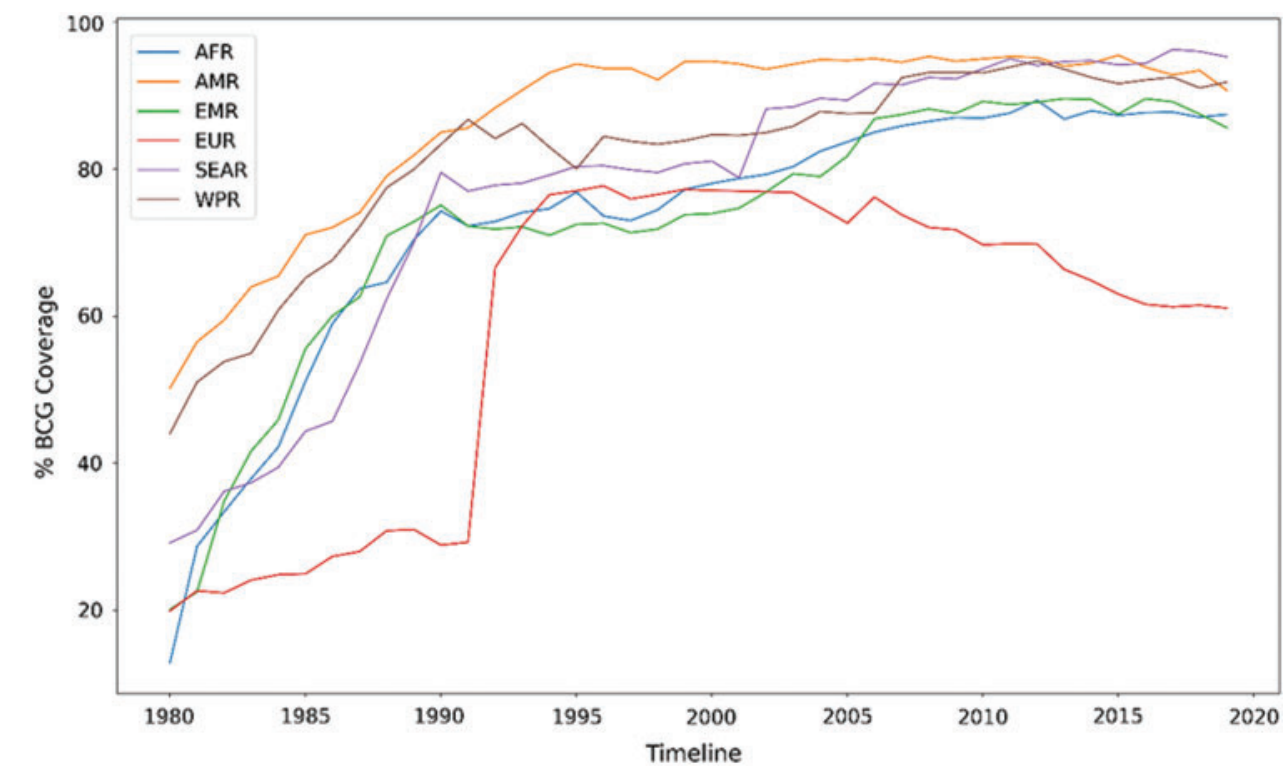

Figure 8: Percentage of BCG coverage for different regions from 1980 to 2019

Table 3: Distribution of countries for several strains of BCG

\begin{tabular}{|c|c|c|c|c|c|c|c|}
\hline BCG strain & Africa & Asia & Europe & North America & Oceania & South America & Total \\
\hline Danish & 7 & 4 & 16 & 2 & 1 & 2 & 30 \\
\hline Japan & 1 & 7 & 3 & 1 & 0 & 0 & 12 \\
\hline Pasteur & 2 & 2 & 3 & 1 & 0 & 0 & 4 \\
\hline Intervax Toronto & 2 & 1 & 0 & 1 & 0 & 0 & 4 \\
\hline Serum Institute of India & 1 & 3 & 0 & 0 & 0 & 0 & 4 \\
\hline
\end{tabular}

Fig. 10a shows the comparison of fatality rates based on BCG vaccination policy status. Fig. 10b shows the fatality rate $v$ s. the status of BCG vaccination. A noticeable difference can be observed in the fatality rate amongst highly infected countries based on BCG vaccination status. The maximum difference is observed around the first week of May. The non-BCG mandatory countries have a combined fatality rate of $11.57 \%$ compared to the fatality rate of $3.96 \%$ for $\mathrm{BCG}$ mandatory countries.

\footnotetext{
${ }^{4}$ https://apps.who.int/immunization_monitoring/globalsummary/timeseries/tswucoveragebcg.html.
} 


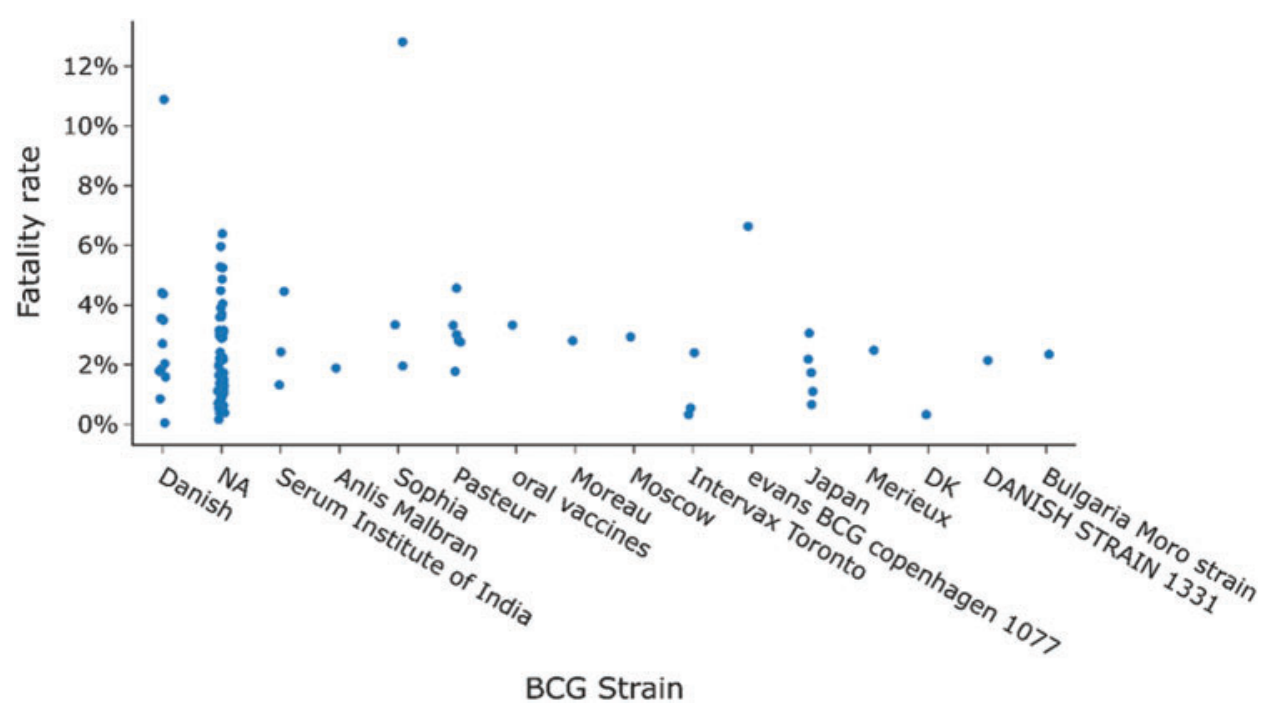

Figure 9: Distribution of fatality rate for countries when divided by BCG strain used there

These rates have dropped to $5.12 \%$ for non-BCG mandatory countries and $3.2 \%$ for $\mathrm{BCG}$ mandatory countries by the first half of August 2020 due to refined preparedness to combat the virus. It can be inferred that BCG vaccination can affect the fatality rate due to COVID-19. However, no certain behaviors can be established since other factors can also affect the fatality rate. The presented analytical analysis speculates the possible impact of $\mathrm{BCG}$ vaccination status on COVID-19 infections and the fatality rates. However, it becomes imperative to evaluate other factors that could play a vital role in defining the presented fatalities due to this deadly virus [25]. One factor could be the prevailing poverty that has deprived the poverty-stricken population of providing facilities and health services [26] in fighting and chronic or pandemics. As a result, countries with a highly poor population may face high numbers of deaths due to this deadly virus in this case. Similarly, the life expectancy and the average old population each nation possesses are other variables that may affect the fatality rate [27-29]. From the two datasets ${ }^{5,6}$ a composite snapshot for significant countries with their BCG status and the variables listed above also compared in Tab. 4.

- After observing the trend in various countries and considering the factors listed in Tab. 4, certain inferences lists BCG's role in driving lower fatality rate in BCG countries despite the following facts.

- BCG countries have a higher average population. Still, the number of cases per million in these countries was three times lower than the average of any non-BCG country.

These assessments mentioned above show that fatality rates in BCG countries higher than non-BCG-compulsory countries cannot be clearly explained using various conditions such as higher testing and a higher percentage of older people. Therefore, even after the empirical data analytics, the factors mentioned still point to other possibilities that claim to be followed by vaccination policies.

\footnotetext{
5 https://www.kaggle.com/bcgvaccine/hackathon.

${ }^{6}$ https://www.pnas.org/content/supp1/2020/07/07/2008410117.DCSupplemental.
} 


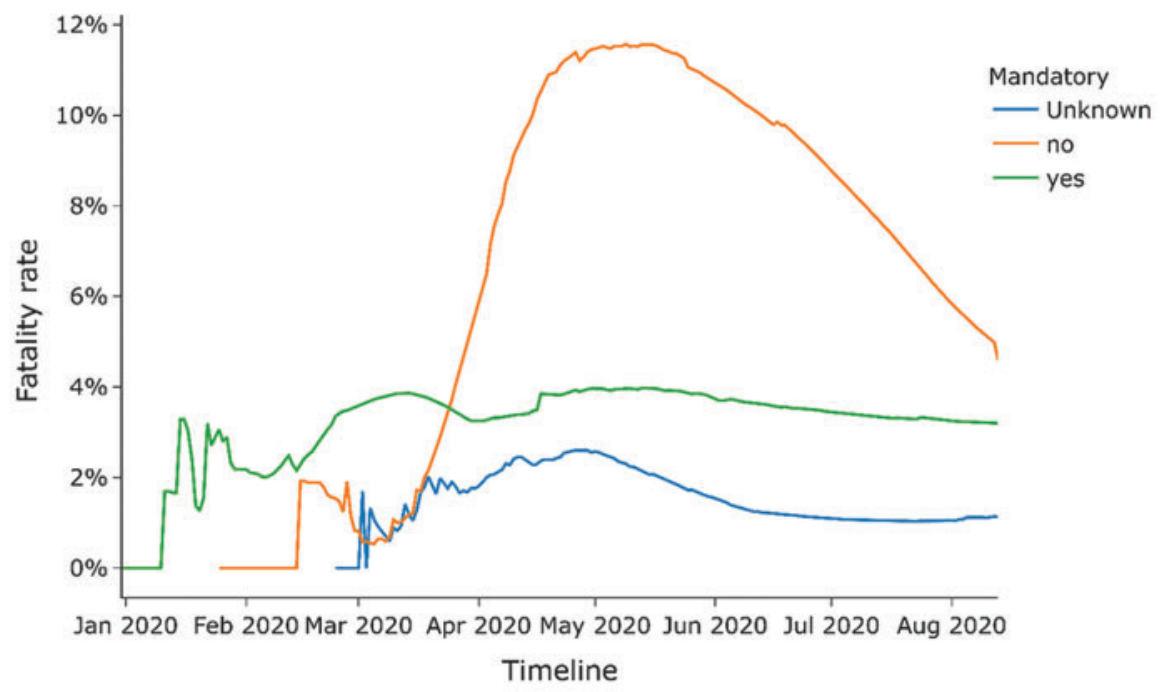

(a)

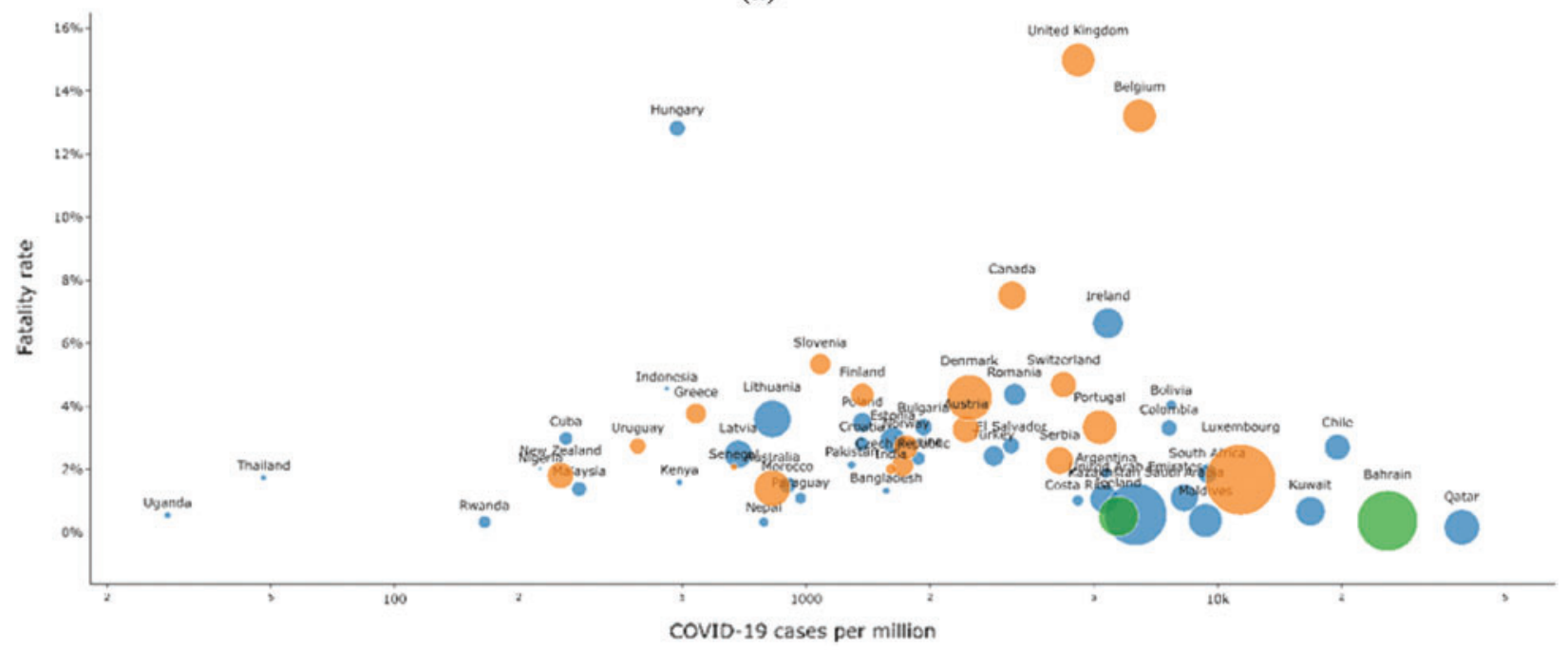

(b)

Figure 10: (a) Comparison of fatality rate by BCG vaccination policy status (b) Comparison of fatality rate by the total number of cases

Table 4: Different factory compared based on BCG vaccination status of countries

\begin{tabular}{|c|c|c|c|c|c|c|c|}
\hline $\begin{array}{l}\mathrm{BCG} \\
\text { mandatory } \\
\text { status }\end{array}$ & $\begin{array}{l}\text { Population } \\
\text { (median) }\end{array}$ & $\begin{array}{l}\text { Total cases } \\
\text { per million } \\
\text { (median) }\end{array}$ & $\begin{array}{l}\text { Total tests } \\
\text { per } \\
\text { thousand } \\
\text { (median) }\end{array}$ & $\begin{array}{l}\text { Extreme } \\
\text { poverty } \\
\text { (mean) }\end{array}$ & $\begin{array}{l}\text { Hospital } \\
\text { beds per } \\
\text { thousand } \\
\text { (mean) }\end{array}$ & $\begin{array}{l}\text { Ages } 65 \\
\text { and older } \\
\text { (median) }\end{array}$ & $\begin{array}{l}\text { Life } \\
\text { expectancy } \\
\text { (mean) }\end{array}$ \\
\hline Yes & 11326616 & 827.2 & 38.18 & 16.2 & 2.590953 & 4.8 & 70.6 \\
\hline No & 10099270 & 2493.352 & 103.371 & 4.094118 & 3.587269 & 18.436 & 79.701379 \\
\hline Unknown & 106766 & 2600.52 & 380.54 & 0.4 & 4.1907 & 9.7525 & 78.395 \\
\hline
\end{tabular}




\section{Case Study: BCG Status Analysis}

\subsection{Spain and Portugal: Neighbors with Different BCG Vaccination Status}

Spain and Portugal are neighboring regions with similar economic, demographic, cultural, and social statuses but have different BCG Vaccination policies. While Portugal has a current national BCG vaccination policy for all, Spain stopped its national BCG vaccination policy for all in the year 1981. Due to these factors and similarities between these countries, this paper compares the effect of BCG policies while eliminating other factors that might have played roles had it been some other combination of countries. Figs. 11a-11c compares various statistics between Spain and Portugal. Comparing the number of cases per million is a better metric for comparison than the total number of cases since Spain's population is more than double that of Portugal. ${ }^{7,8}$

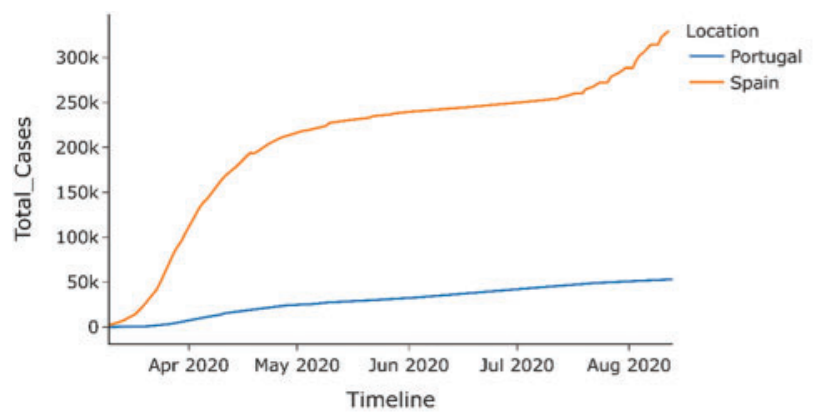

(a)

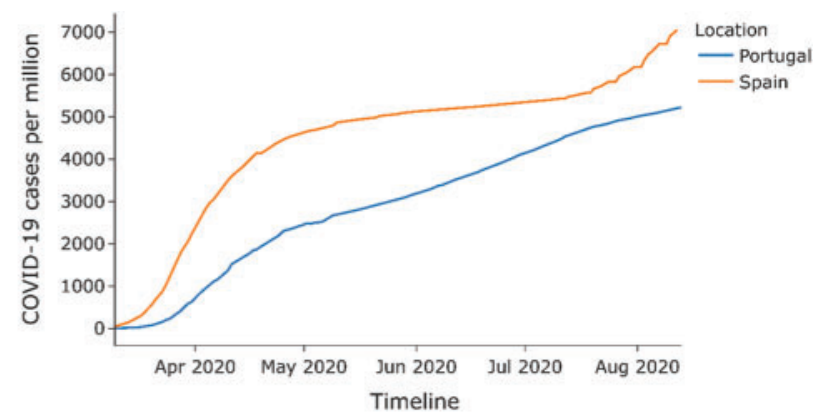

(b)

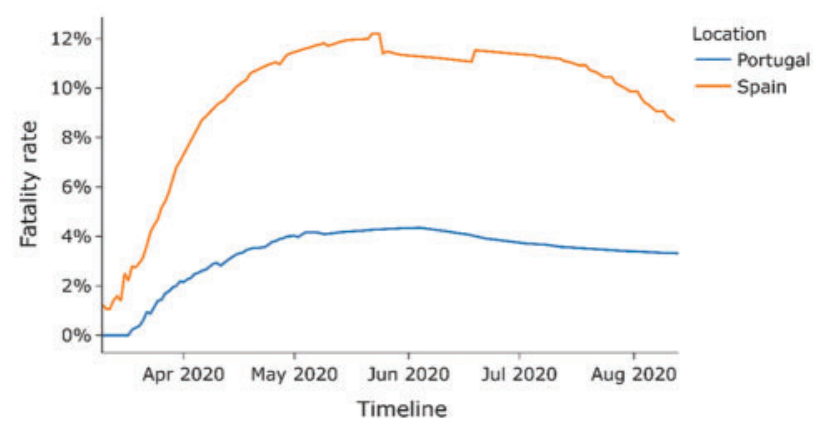

(c)

Figure 11: Case study_Spain vs. Portugal (a) Total COVID-19 cases (b) COVID-19 cases per million (c) Fatality rate

As shown in Fig. 12, the stringency index or the lockdown measure in both countries was similar hence eliminating the stringency index as a factor that could affect COVID-19 cases deaths between the countries. Hence, as seen from the bar graphs in Figs. 13 and 14, the percentage COVID-19 positive cases leading to death, Portugal has a lower death rate than Spain across all age groups. Hence COVID-19 had a lesser impact on Portugal than in Spain, possibly due to the difference in $\mathrm{BCG}$ vaccination policy in both countries.

\footnotetext{
7 https://en.wikipedia.org/wiki/COVID-19_pandemic_in_Spain.

${ }^{8}$ https://en.wikipedia.org/wiki/COVID-19_pandemic_in_Portugal.
} 


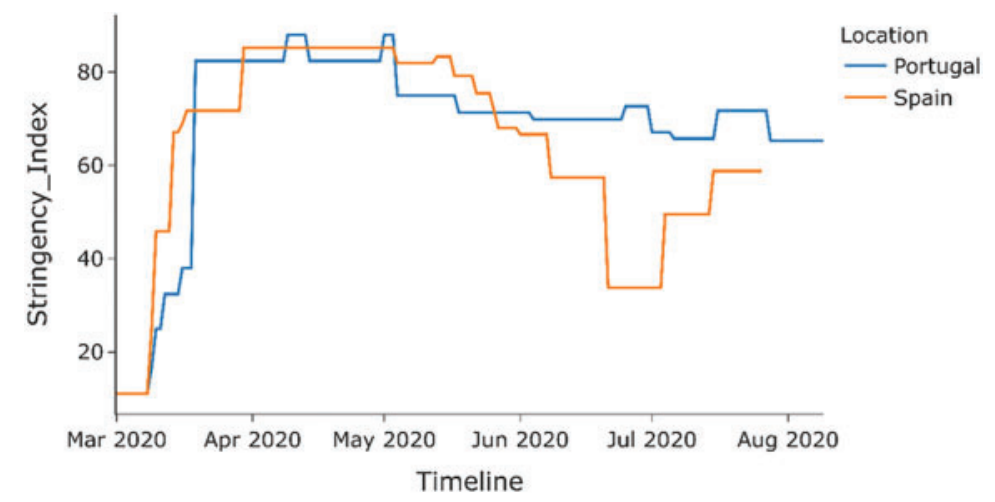

Figure 12: Stringency index of COVID-19 positive cases (Spain vs. Portugal)

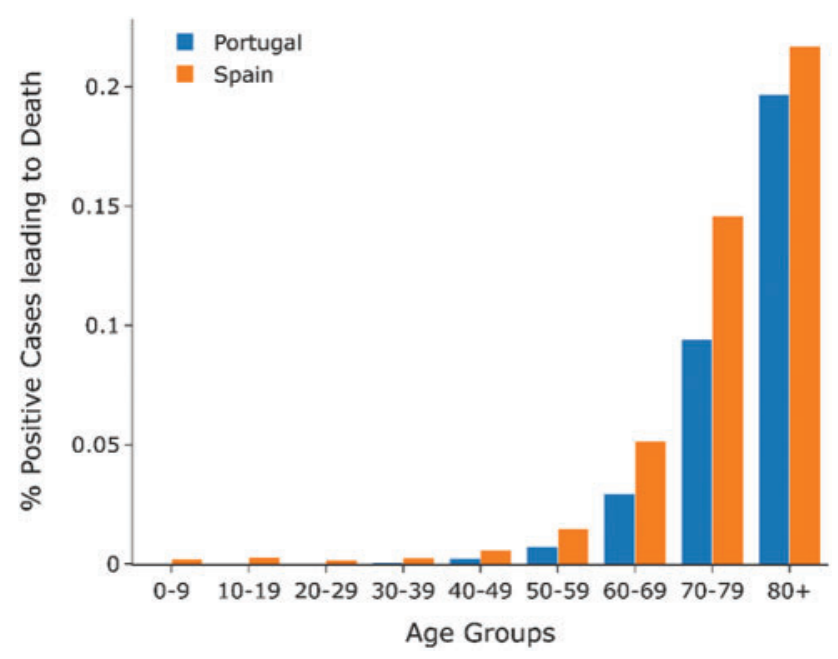

Figure 13: Percentage of COVID-19 positive cases leading to death by age group (Spain vs. Portugal)

\subsection{East and West Germany: Impact of Divergent BCG Policies on COVID-19}

This section shows the difference in the spread of COVID-19 across East and West Germany. Different BCG vaccination policies existed between these two regions in the divided country from 1949 to 1989 before their reunification in 1990. At the same time, East Germany had a compulsory BCG vaccination policy for all, in contrast to the voluntary BCG vaccination policy in West Germany. Currently, after the unification, Germany doesn't have a current BCG vaccination policy for all. ${ }^{9}$ As seen from Figs. 15 and 16c, East and West Germany's fatality rate does not differ much from each other and is always within $1 \%$ of each other. East Germany provinces have a slightly lower fatality rate than that of West Germany provinces. The spread of COVID-19 across provinces of West Germany is almost seven times more when compared to East Germany, as shown by Fig. 16a, while the deaths caused by COVID-19 are nearly nine times larger in West Germany as compared to East Germany. Deaths per million for West Germany are almost double

\footnotetext{
${ }^{9}$ https://www.kaggle.com/headsortails/covid19-tracking-germany?select=covid_de.csv.
} 
that of East Germany hence eliminating population size as a factor and is shown by Fig. 16d. This indicates that BCG vaccination may play a role in the spread of COVID-19 since East Germany, which had a universal BCG vaccination policy, has a lesser impact on COVID-19 than West Germany.

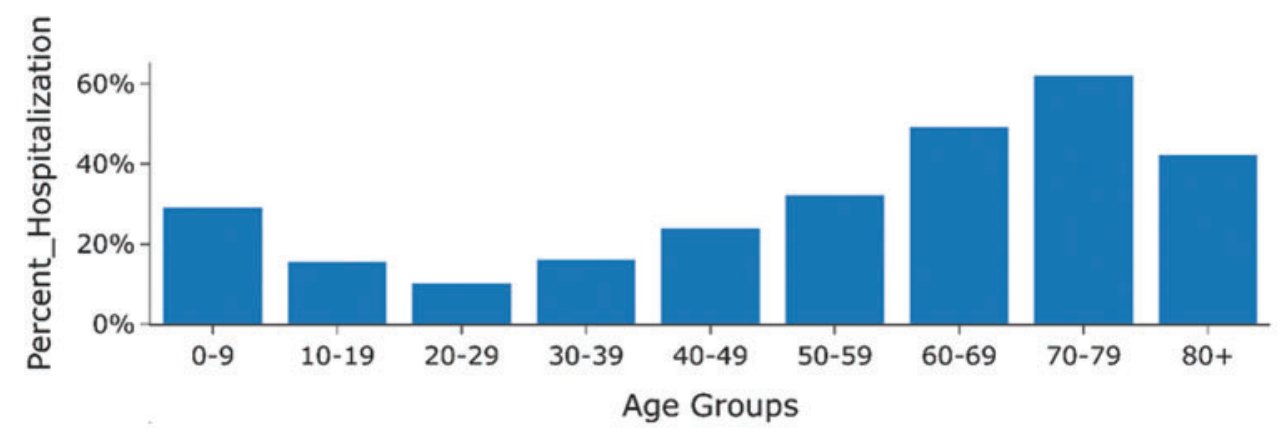

(a)

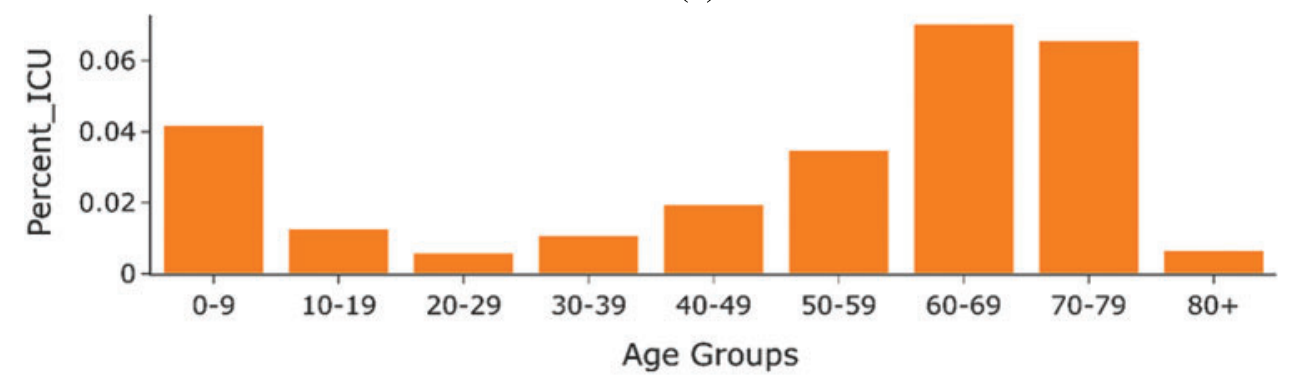

(b)

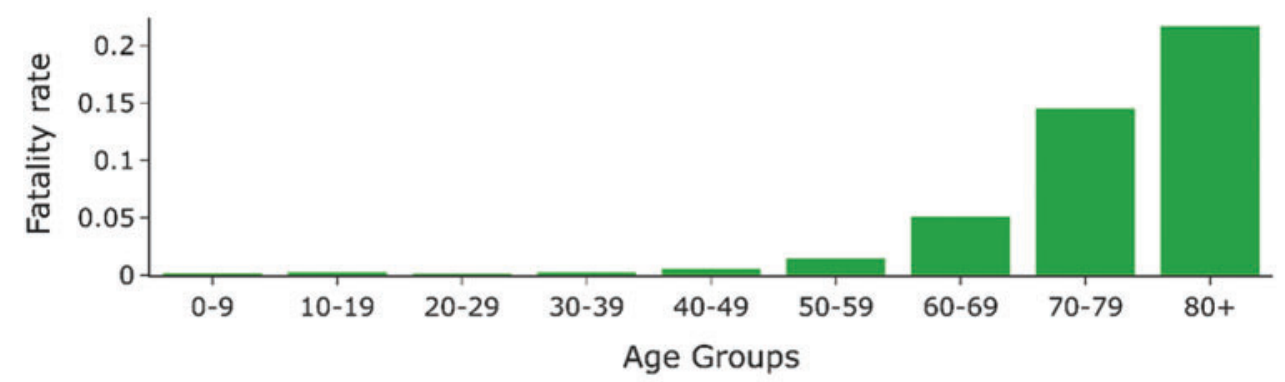

(c)

Figure 14: Statistics of Spain (percentage hospitalization, percentage of people admitted in ICU, and percentage deaths) by age group

Figs. $17 \mathrm{a}$ and $17 \mathrm{~b}$ shows the distribution of fatality Rate and Deaths per million across different age groups in East and West Germany. Deaths per million are very low for the age group 0-59, while the fatality rate for this age group is almost zero. Further, a steady increase can be noticed in the fatality rate and deaths per million as one progresses higher in age groups. As can be seen from the graph, the fatality rate and fatalities per million are much higher for West Germany than East Germany. 


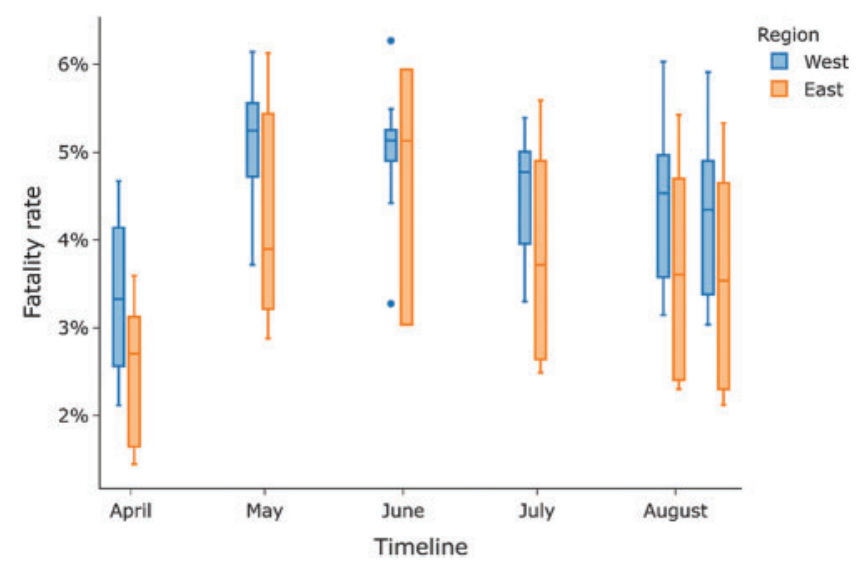

Figure 15: Fatality rate for a different period for east vs. west region of Germany

\section{Discussions and Inspections}

The initial research shows that countries with long-term compulsory BCG vaccination systems were less affected than those without these systems. Multiple other economic, demographic, and cultural factors can play a role in the spread of COVID-19 in a given country, so one cannot reliably claim BCG's role in reducing these deaths in totality. Additionally, deep learning in health care can provide further insights [30,31]. Recent studies have indicated that BCG vaccination may have protective effects against COVID-19. Still, it is highly doubtful that the current BCG vaccine type may provide full protection against SARS-CoV-2 infection due to lack of clear evidence. In any event, regardless of these impediments, the latest evidence is the first to demonstrate unquestionably a crucial favorable role of all-inclusive BCG arrangements in decreasing the spread of COVID-19 [32,33]. In this way, the rigorous analysis of the importance of compulsory BCG immunization in the COVID-19 war is legitimized.

Two case studies present the analogy between Spain and Portugal concerning the BCG policy status and correlated fatality rate statistics. It can be observed that despite other factors like stringency index, population variability, the COVID-19 had a smaller effect on Portugal than in Spain, likely due to the disparity in both countries' BCG vaccination policies. The second case study compares the two provinces of Germany: East and West. The fatality rate and deaths per million are much higher for West Germany than East Germany, as can be seen from the analytical and empirical analysis, which is further attributed to the varying vaccination policies despite other prevailing factors.

Therefore, this paper establishes that BCG induces trained immunity to protect COVID-19, but this hypothesis needs to be tested in rigorous randomized clinical trials. BCG (or other triggers that cause qualified immunity) could be quickly evaluated and potentially used at the start of a pandemic, bridging the one-two year gap before producing an effective vaccine. Therefore, this possibility carries a particular force because there is an urgent need to enforce such strategies to restrain SARS-CoV-2 and restrict the pandemic, which has imposed a quarantine on one-third of the Earth's population. 


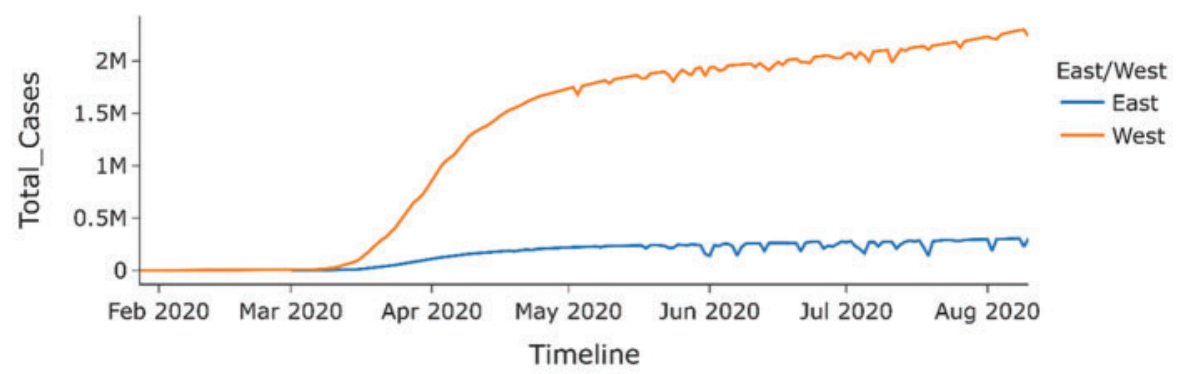

(a)

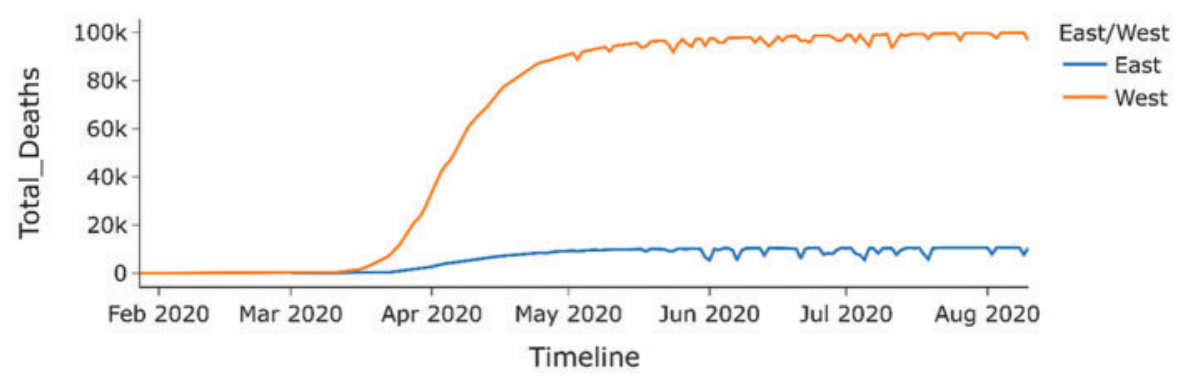

(b)

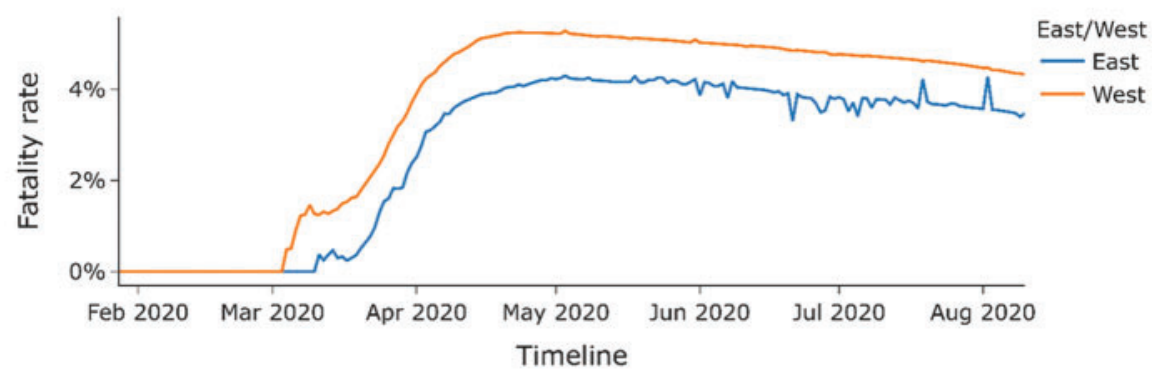

(c)

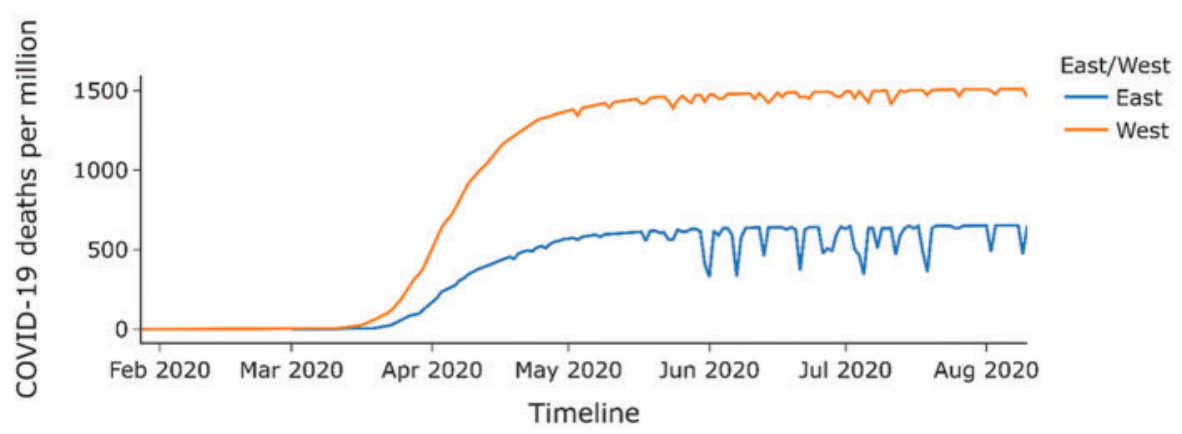

(d)

Figure 16: (a) Total COVID-19 cases for east vs. west region of Germany (b) Total COVID-19 deaths for east vs. west region of Germany (c) Fatality rate for COVID-19 for east vs. west region of Germany (d) COVID-19 deaths per million for east vs. west region of Germany 


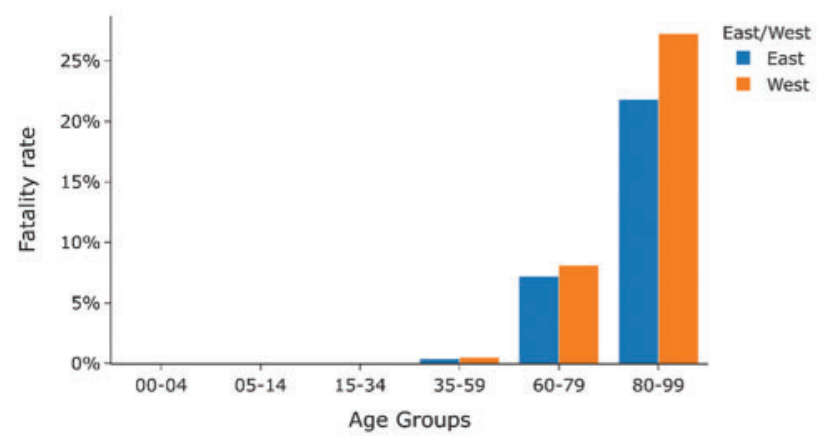

(a)

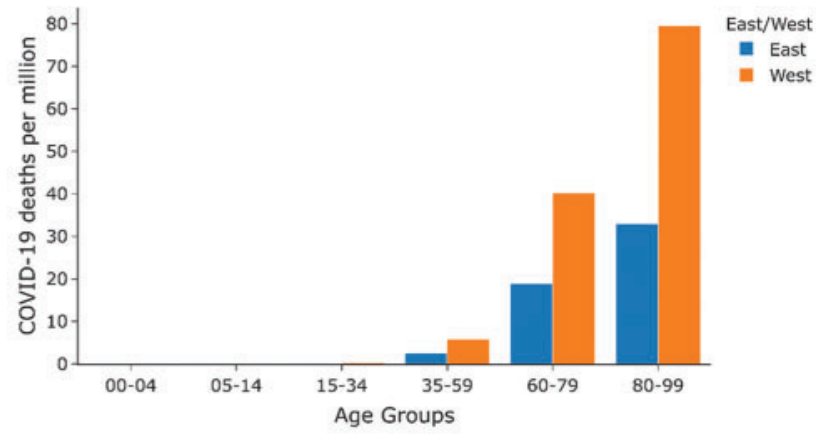

(b)

Figure 17: Case Study East vs. West Germany (a) Fatality rate by age group (b) Deaths per million by age group

\section{Conclusion}

The deadly COVID-19 has been spreading since December 2019. The infectious nature of this virus has been troubling the entire world. The governments of all the countries imposed stringent restrictions to curtail the further spread. This paper studies the role of the BCG vaccine on the fatality rate amongst the COVID-19 victims. BCG is used as a preventive measure for lung-related diseases. This paper's analytical and empirical data assessment shows the countries following a mandatory BCG vaccination policy suffer from a relatively lower fatality rate than the countries with relaxed BCG-related policies. Apart from the vaccination perspective, the current analysis explores the role of other influencing factors, viz. total cases with deaths and population, median age with GDP and hospital beds per thousands, and stringency index can drive an elevated fatality rate. This work's limitation can be drawn from the fact that the available data is limited and hence impedes comprehensive comparison between BCG vaccination and COVID-19 fatality rate. As a future enhancement to this work, resources can be provided for the aggregation, management, review, and assimilation of scalable amounts of disparate, organized, and unstructured data for vaccine surveillance policies adopted by healthcare systems.

Funding Statement: The authors received no specific funding for this study.

Conflicts of Interest: The authors declare that they have no conflicts of interest to report regarding the present study.

\section{References}

[1] D. Klinger, I. Blass, N. Rappoport and M. Linial, "Significantly improved COVID-19 outcomes in countries with higher BCG vaccination coverage: A multivariable analysis," Vaccines, vol. 8, no. 3, pp. 378-392, 2020.

[2] M. Koti, A. Morales, C. H. Graham and D. R. Siemens, "BCG vaccine and COVID-19: Implications for infection prophylaxis and cancer immunotherapy," Journal for Immunotherapy of Cancer, vol. 8, no. 2, pp. 1-4, 2020.

[3] N. E. Aronson, M. Santosham, G. W. Comstock, R. S. Howard, L. H. Moulton et al., "Long-term efficacy of BCG vaccine in American Indians and Alaska natives: A 60-year follow-up study," JAMA, vol. 291, no. 17, pp. 2086-2091, 2004.

[4] N. T. Usher, S. Chang, R. S. Howard, A. Martinez, L. H. Harrison et al., "Association of BCG vaccination in childhood with subsequent cancer diagnoses: A 60-year follow-up of a clinical trial," JAMA Network Open, vol. 2, no. 9, pp. 1-12, 2019. 
[5] A. Sharma, S. K. Sharma, Y. Shi, E. Bucci, E. Carafoli et al., "BCG vaccination policy and preventive chloroquine usage: Do they have an impact on COVID-19 pandemic?," Cell Death \& Disease, vol. 11, no. 7, pp. 1-10, 2020.

[6] S. O. Moghadam, "A review on currently available potential therapeutic options for COVID-19," International Journal of General Medicine, vol. 13, no. 13, pp. 443-467, 2020.

[7] B. S. Johnson and M. Laloraya, "Cytokine storm in COVID-19 patients transforms to a cytokine super cyclone in patients with risk factors," Cytokine \& Growth Factor Reviews, vol. 54, pp. 32-42, 2020.

[8] S. Mohan, C. Thirumalai and G. Srivastava, "Effective heart disease prediction using hybrid machine learning techniques," IEEE Access, vol. 7, pp. 81542-81554, 2019.

[9] B. Sarkar, R. N. Sinha and K. Sarkar, "Initial viral load of a COVID-19-infected case indicated by its cycle threshold value of polymerase chain reaction could be used as a predictor of its transmissibilityan experience from gujarat, India," Indian Journal of Community Medicine, vol. 45, no. 3, pp. 278-282, 2020.

[10] U. Hamiel, E. Kozer and I. Youngster, "SARS-Cov-2 rates in BCG-vaccinated and unvaccinated young adults," JAMA, vol. 323, no. 22, pp. 2340-2341, 2020.

[11] Y. Toyoshima, K. Nemoto, S. Matsumoto, Y. Nakamura and K. Kiyotani, "SARS-Cov-2 genomic variations associated with mortality rate of COVID-19," Journal of Human Genetics, vol. 65, no. 12, pp. 1075-1082, 2020.

[12] G. Redelman-Sidi, "Could BCG be used to protect against COVID-19?," Nature Reviews Urology, vol. 17, no. 6, pp. 316-317, 2020.

[13] L. Catteau, N. Dauby, M. Montourcy, E. Bottieau, J. Hautekiet et al., "Low-dose hydroxychloroquine therapy and mortality in hospitalized patients with COVID-19: A nationwide observational study of 8075 participants," International Journal of Antimicrobial Agents, vol. 56, no. 4, pp. 106-114, 2020.

[14] S. Charoenlap, K. Piromsopa and C. Charoenlap, "Potential role of bacillus calmette-guérin (BCG) vaccination in COVID-19 pandemic mortality: Epidemiological and immunological aspects," Asian Pacific Journal of Allergy and Immunology, vol. 38, no. 3, pp. 150-161, 2020.

[15] L. E. Escobar, A. Molina-Cruz and C. Barillas-Mury, "BCG vaccine protection from severe coronavirus disease 2019 (COVID-19)," Proc. of the National Academy of Sciences, vol. 117, no. 30, pp. 17720-17726, 2020.

[16] V. Gupta, V. K. Singh, P. Mukhija and U. Ghose, "Aspect-based sentiment analysis of mobile reviews," Journal of Intelligent and Fuzzy Systems, vol. 36, no. 5, pp. 4721-4730, 2019.

[17] R. Piryani, V. Gupta and V. K. Singh, "Movie prism: A novel system for aspect level sentiment profiling of movies," Journal of Intelligent \& Fuzzy Systems, vol. 32, no. 5, pp. 3297-3311, 2017.

[18] V. Gupta, V. K. Singh, U. Ghose and P. Mukhija, "A quantitative and text-based characterization of big data research," Journal of Intelligent and Fuzzy Systems, vol. 36, no. 5, pp. 4659-4675, 2019.

[19] C. H. Weng, A. Saal, W. Butt, N. Bica, J. Q. Fisher et al., "Bacillus calmette-Guérin vaccination and clinical characteristics and outcomes of COVID-19 in rhode island, United States: A cohort study," Epidemiology \& Infection, vol. 148, no. 1, pp. 1-9, 2020.

[20] M. Gursel and I. Gursel, "Is global BCG vaccination-induced trained immunity relevant to the progression of the SARS-coV-2 pandemic?," Allergy, vol. 75, no. 7, pp. 1815-1819, 2020.

[21] B. M. Ayoub, "COVID-19 vaccination clinical trials should consider multiple doses of BCG," Die Pharmazie-an International Journal of Pharmaceutical Sciences, vol. 75, no. 4, pp. 159-159, 2020.

[22] N. Jain, D. Virmani and A. Abraham, "Overlap function based fuzzified aquatic behaviour information extracted tsunami prediction model," International Journal of Distributed Systems and Technologies, vol. 10, no. 1, pp. 56-81, 2019.

[23] N. Jain, D. Virmani and A. Abraham, "Proficient 3-class classification model for confident overlap value based fuzzified aquatic information extracted tsunami prediction," Intelligent Decision Technologies, vol. 13, no. 3, pp. 295-303, 2019.

[24] R. Piryani, V. Gupta and V. K. Singh, "Generating aspect-based extractive opinion summary: Drawing inferences from social media texts," Computacióny Sistemas, vol. 22, no. 1, pp. 83-91, 2018. 
[25] N. Jain, S. Jhunthra, H. Garg, V. Gupta, S. Mohan et al., "Prediction modelling of COVID using machine learning methods from B-cell dataset," Results in Physics, vol. 21, pp. 1-18, 2021.

[26] C. Iwendi, S. A. Moqurrab, A. Anjum, S. Khan, S. Mohan et al., "N-Sanitization: A semantic privacypreserving framework for unstructured medical datasets," Computer Communications, vol. 161, pp. 160$171,2020$.

[27] A. Naserghandi, R. Saffarpour and S. F. Allameh, "Exploring the causes of mild COVID-19 involvement in pediatric patients," New Microbes and New Infections, vol. 37, pp. 1-6, 2020.

[28] Y. Tomita, R. Sato, T. Ikeda and T. Sakagami, "BCG vaccine may generate cross-reactive T cells against SARS-coV-2: In silico analyses and a hypothesis," Vaccine, vol. 38, no. 41, pp. 6352-6356, 2020.

[29] V. Gupta, N. Jain, P. Katariya, A. Kumar, S. Mohan et al., "An emotion care model using multimodal textual analysis on COVID-19," Chaos, Solitons \& Fractals, vol. 144, pp. 1-9, 2021.

[30] T. R. Gadekallu, D. S. Rajput, M. P. K. Reddy, K. Lakshmanna, S. Bhattacharya et al., "A novel PCA-whale optimization-based deep neural network model for classification of tomato plant diseases using GPU," Journal of Real-Time Image Processing, pp. 1-14, 2020.

[31] S. Bhattacharya, P. K. R. Maddikunta, Q. V. Pham, T. R. Gadekallu, C. L. Chowdhary et al., "Deep learning and medical image processing for coronavirus (COVID-19) pandemic: A survey," Sustainable Cities and Society, vol. 65, pp. 102589, 2021.

[32] G. Lalit, C. Emeka, N. Nasser, C. Chinmay and G. Garg, "Anonymity preserving IoT-based COVID-19 and other infectious disease contact tracing model," IEEE Access, vol. 8, pp. 159402-159414, 2020.

[33] C. Chinmay and N. A. Arij, "Intelligent internet of things and advanced machine learning techniques for COVID-19," EAI Endorsed Transactions on Pervasive Health and Technology, vol. 7, no. 26, pp. 1-14, 2021. 